\title{
Validity of the ACT Assessment as an Indicator of Reading Ability
}

\author{
Richard J. Stiggins, Cynthia B. Schmeiser, and Richard L. Ferguson \\ The American College Testing Program
}

The purpose of this research was to explore the validity of ACT Assessment test results as indicators of reading skill. This was considered important because of the large and growing number of postsecondary institutions using open admission policies and admitting students with a wide range of reading ability. If ACT scores were found to be predictive of reading performance, ACT data could be used to identify those students who might profit from remedial reading training. Various test score combinations were used to predict students' performance on numerous reading tests at a large number of postsecondary institutions. These studies indicated a high level of predictive accuracy.

Postsecondary education has undergone substantial changes over the past decade. One significant change has been the expansion of educational opportunity available to students long denied access to a college education. Rever and Kojaku (1976) note that it was during these last 10 years that many new community and junior colleges were established while older ones expanded. At the same time, open admission policies were being adopted by many institutions. Together, these two phenomena served to lower academic barriers to higher education. Financial barriers were eased with increasing

APPLIED PSYCHOLOGICAL MEASUREMENT Vol. 2, No. 3 Summer 1978 pp. 337-344

(C) Copyright 1978 West Publishing Co. state and federal financial assistance to postsecondary education.

These efforts to provide postsecondary educational opportunity to a larger segment of students have been highly effective. One rather important result has been an increase in the college enrollment of students from the lower level of high school graduating classes (Cross, 1971). This declining level of developed academic abilities of enrolled college students has significantly affected the institutions of higher education, especially the community colleges. The diversity of academic background of entering students has contributed to new problems, the most fundamental one being that of determining how colleges can help students with low or modestly developed abilities become successful learners in college.

Given this need by colleges, much interest has focused on methods for determining the entering student's level of academic accomplishment to facilitate correct placement in appropriate courses. Since tests are considered a major tool for obtaining student placement information, institutions have not only relied on nationally recognized standardized tests, but have also developed their own tests.

The ACT Assessment Program, developed and administered by the American College Testing Program, is frequently used for placement purposes, particularly in English and mathe- 
matics (Oliven, 1975). However, another skill area critical to success in college, but not directly reported through the ACT tests, is reading. Although the ACT Assessment includes a Social Studies Reading Test and a Natural Sciences Reading Test, neither test is designed solely and specifically to measure traditional reading skills. In the hope that ACT Assessment data might be valuable for placement decisions in reading, research was conducted to determine the relationship between weighted combinations of ACT Assessment tests and established measures of reading ability.

\section{Related Research}

Although many studies have been conducted to determine the relationship between students' performances on the ACT Assessment and on various reading tests, only a limited number have been published. Of the 17 studies reviewed in this section, 13 were conducted as part of the ACT's Research Services to colleges; they were completed solely for use by individual institutions. The remaining four studies (Schroeder, 1975; Mist, 1970; Munday, 1968; Kammann, 1973) have received wider dissemination than have the ACT Research Services studies.

The 13 unpublished studies conducted by ACT Research Services relied entirely on correlational techniques. In each study, the four ACT test scores and the ACT Composite Score were correlated with reading test scores. The results of those studies are reported in Table 1. Although the reading test used varied among institutions, the correlations reported are highly consistent. In all cases, the criterion score was a composite (total) reading test score. The highest correlation within individual institutions was typically between the ACT Composite and the reading score. Similarly high relationships were found between ACT Social Studies and reading as well as ACT English Usage and reading. Somewhat lower coefficients characterized the reading/natural science and reading/mathematics relationships.

Two other studies, one by Mist (1970) and the other by Munday (1968), also relied on simple correlational data to examine the relationship between ACT test scores and reading. Mist reported correlations of .58 between NelsonDenny Reading Test scores and ACT English, .37 between Mathematics and reading, .66 between a composite (sum) of Social Studies and Natural Science and reading, and .65 between the ACT Composite and reading $(N=279)$. Munday reported correlations which were of about the same order of magnitude: English, .63; Mathematics, .40; Social Studies, .70; Natural Science, .59; Composite, .73. These correlations were based on Nelson-Denny and ACT scores achieved by 1,239 students in three colleges.

Schroeder (1975) and Kammann (1973) extended these correlational studies by considering multiple criterion variables in their analyses. Kammann used subscores of the Diagnostic Reading Test as his criterion variables, whereas Schroeder used subscores and a total score of the Nelson-Denny Reading Test. Schroeder also used a combination of three ACT scores simultaneously by means of multiple regression techniques. The results of these two studies are reported in Tables 2 and 3.

Kammann's results suggest that, in general, ACT scores are most highly related to paragraph comprehension and vocabulary. In particular, the Social Studies and Natural Science scores contributed most to this relationship. The results of the Schroeder studies are consistent with those cited previously in that the highest multiple correlation was obtained using the total reading test score as the criterion variable. However, all three coefficients suggest that prediction of reading performance is quite accurate. In fact, the data led the researcher to the conclusion that "the estimation of Nelson-Denny scores based on ACT data can be performed with sufficient accuracy to conclude that it is possible to reliably determine which students 


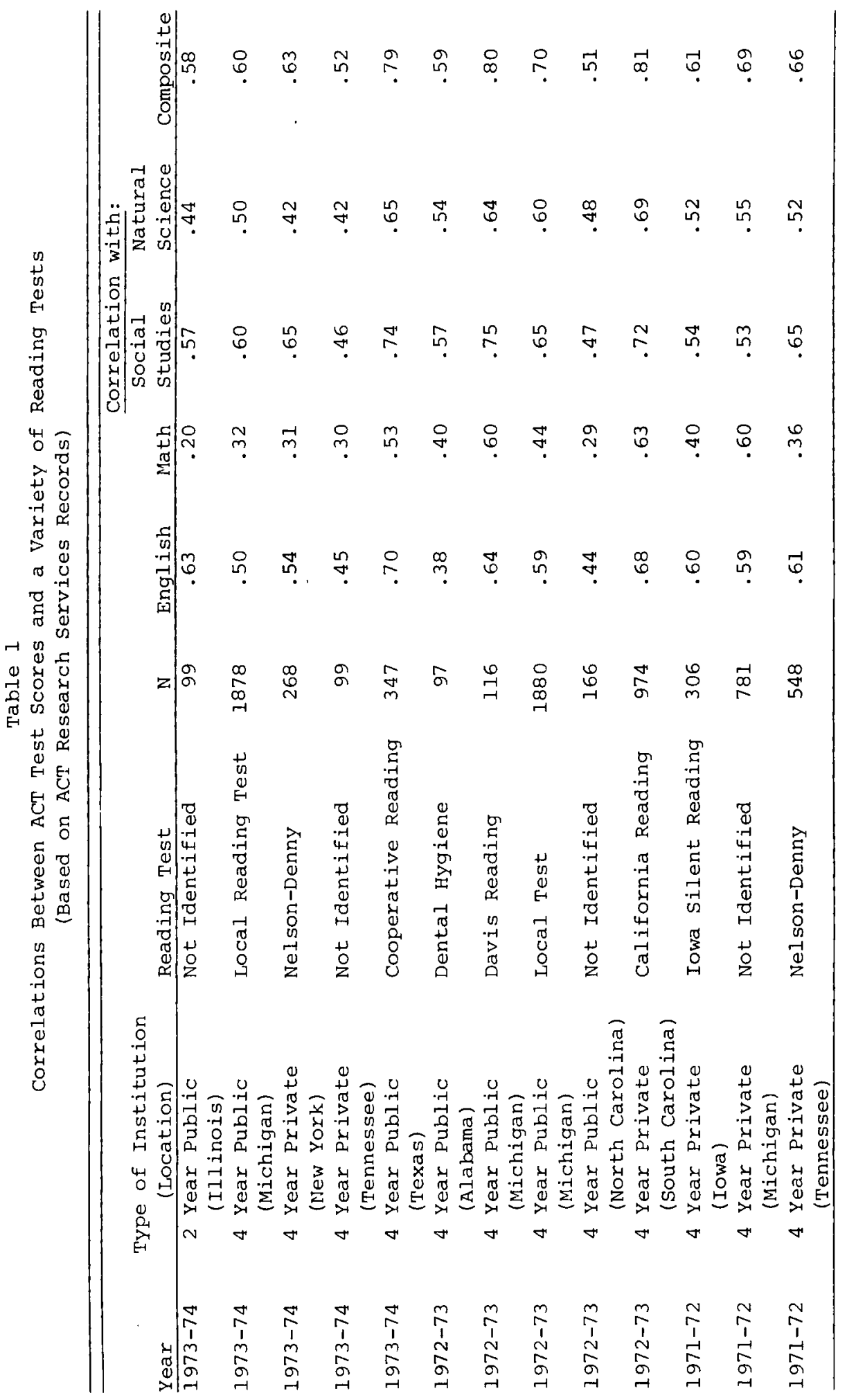




\section{Table 2}

Correlations Between ACT Test Scores and Diagnostic Reading

Test Subscores ( $N=143$ ) (From Kammann, 1973)

(C) Purdue Research Foundation--Reprinted with Permission

\begin{tabular}{lcccc}
\hline & & \multicolumn{2}{c}{ Diagnostic Reading Scores } \\
\cline { 2 - 5 } ACT Subtests & Rate & $\begin{array}{c}\text { Story } \\
\text { Comprehension }\end{array}$ & $\begin{array}{c}\text { Paragraph } \\
\text { Comprehension }\end{array}$ & Vocabulary \\
\hline English Usage & .30 & .40 & .49 & .51 \\
Math & .09 & .35 & .51 & .50 \\
Social Studies & .32 & .55 & .63 & .68 \\
Natural Science & .34 & .54 & .59 & .67 \\
Composite & .32 & .57 & .68 & .72 \\
\hline
\end{tabular}

will require reading skill development and which students are reading at appropriate grade level" (Schroeder, 1975, p. 4).

Collectively, these studies support the potential value of ACT Assessment data as a valid predictor of reading ability. However, some questions remain to be addressed. Might the multiple $R$ for predicting reading ability from Assessment scores be increased by using selected subsets of ACT test items? That is, might more accurate prediction result from some particular combination of subscores? Does accuracy of prediction vary for different subgroups of students? Could ACT data be expected to yield a reliable index of reading proficiency?

\section{Method}

The predictive validity of various combinations of Act Assessment tests was addressed by means of multiple regression analysis. The combinations of ACT data used in prediction equations included all four standard scores in linear combination (English Usage, 75 items; Mathematics, 40 items; Natural Science Reading, 52 items; and Social Science Reading, 52 items); three ACT scores in linear combination (English + Natural Science + Social Studies); two ACT scores in linear combination (Natural Science + Social Studies); a score based on passage-related items in the two reading tests ${ }^{1}$ (Natural Science + Social Studies); and the ACT Composite, which is an arithmetic average of the four standard scores. The criterion variables, or reading tests used, included the Michigan State University Reading Test, the Nelson-Denny Reading Test, and the STEP Reading Test. The data used to assess the predictive power of the ACT included ACT scores for 9,344 students from nine ACT-user institutions who gathered local data on student reading performance during the three-year period from 1972-73 through 1974-75.

Data for only one of these institutions were available at the item response level of precision needed to generate part scores. These data were obtained from Michigan State University $(N=$ 1831) during the 1974-75 academic year. The MSU data also afforded the only opportunity to link student performance to the demographic variables needed to address the question of differential predictability across student subgroups.

\footnotetext{
'Natural Sciences and Social Studies Reading Tests contain 37 items that arise from material presented to the examinee in passages, as well as 15 discrete test items that measure the examinee's general subject-matter knowledge. In this case, the examinee's performance on the discrete items was ignored.
} 
Table 3

Burlington County College Regression Equations for Predicting Reading Scores from ACT Data $(\mathrm{N}=438)$

(From Schroeder, 1975)

\begin{tabular}{llcc}
\hline & & Criterion & Multiple \\
Regression weights & variable & $\begin{array}{c}\text { Standard } \\
\text { error }\end{array}$ \\
\hline $1.67(\mathrm{E})+1.33(\mathrm{SS})+.72(\mathrm{NS})-12.44$ & $\begin{array}{l}\text { Nelson-Denny } \\
\text { Vocabulary }\end{array}$ & .72 & 18.47 \\
$1.48(\mathrm{E})+1.58(\mathrm{SS})+.72(\mathrm{NS})-12.85$ & $\begin{array}{l}\text { Nelson-Denny } \\
\text { Comprehension } \\
\text { Nelson-Denny } \\
\text { Total }\end{array}$ & .76 & 17.42 \\
$1.67(\mathrm{E})+1.56(\mathrm{SS})+.75(\mathrm{NS})-16.71$ & .79 & 16.38 \\
\hline
\end{tabular}

The differential predictability of reading performance for various subsamples of the ACT examinee population was addressed through multiple regression analysis and cross-validation. The accuracy of prediction of ACT predictor score combinations was investigated by sex (male, female); race (minority, white); and level of academic achievement (high school GPA: 4.00 to $3.50,3.49$ to $3.00,2.99$ and below). The resulting regression equations were cross-validated by comparing predicted with actual reading scores for the subsamples of students. The internal consistency reliabilities of the various score combinations were estimated by KuderRichardson Formula 20 coefficients.

\section{Results}

\section{The Accuracy of Prediction}

The investigation of the extent to which reading performance could be predicted from ACT Assessment data focused on a variety of score combinations. The results of that investigation are reported in Table 4 . The median multiple correlation across all combinations and institutions was .71, suggesting that very accurate prediction is possible. Multiple $R$ 's ranging from .53 to .80 suggest that there is consistency in the predictive power across years, institutional types, and reading score criteria.
A review of the relative effectiveness of the various score combinations suggests that the Social Studies and Natural Science combination provided excellent prediction $($ median $=.70$ ). In the one instance where the discrete items could be eliminated, there was a slight decrease in predictive power. The English score enhanced the accuracy of prediction, while the math score (as might be expected) did not. However, the most significant finding is that although there was some difference between the predictive power of the score combinations and the predictive power of the ACT Composite, that difference is of little practical significance.

\section{Differential Predictability}

To determine if predictive accuracy remained constant across subgroups of students, separate regression equations were generated for subsamples using three score combinations: (1) English, Natural Science, and Social Studies standard scores; (2) Natural Science and Social Studies standard scores; and (3) Natural Science and Social Studies passage-related items only. In each case, separate regression equations were generated by sex, race, and high school grade point average. The criterion variable was the Michigan State University Reading Test total score. The resulting multiple correlations for the 


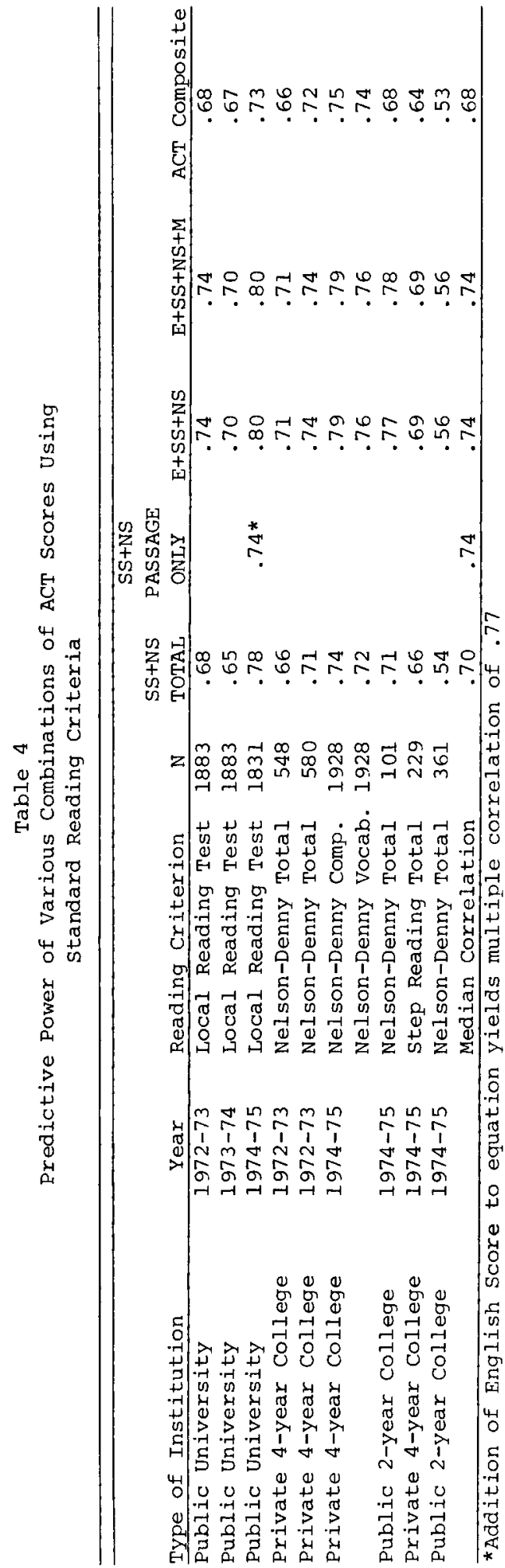

various subgroups, reported in Table 5, present fairly conclusive evidence that each of the score combinations resulted in fairly accurate prediction.

The regression equations that resulted in the multiple correlations reported for the English, Natural Science, and Social Studies standard score combination were cross-validated on an independent sample. The difference between mean actual versus mean predicted scores and the correlations between those scores are reported in Table 6 . The data suggest that scores generated from the regression equations very closely approximated examinees' actual reading performance. On the basis of these analyses, it was concluded that a variety of score combinations demonstrate high predictive validity for each of the subgroups of students.

\section{The Reliability of Reading Scores}

The third and final question considered in exploring the relationship between students' ACT Assessment performance and their reading performance concerned the reliability of the various score combinations. Internal consistency reliability estimates $\left(K R_{20}\right)$ were generated for the three score-reporting options; once again, they demonstrated that the options could not be differentiated. The $K R_{20}$ for the passage-related items option was .89; for the Natural Science and Social Studies combination, the reliability was .92; and for the English, Natural Science, and Social Studies standard score combination, it was .95. These data suggest that the reliabilities of the various score combinations are high.

\section{Summary and Conclusions}

This study explored the relationship between ACT data and reading performance by determining if some combination of those data could be useful in making reading placement decisions. The questions addressed were these: What is the relative predictive efficiency of various ACT score combinations when reading performance is the criterion? Does accuracy of 
Table 5

The Differential Predictive Power of ACT Performance Data for Various student Subgroups

\begin{tabular}{lccc}
\hline & \multicolumn{3}{c}{ SCORE COMBINATIONS } \\
\cline { 2 - 4 } Sex + SS & $E+N S+$ SS & NS + SS (Passage) \\
$\quad$ Male & .72 & .77 & .69 \\
$\quad$ Female & .76 & .82 & .72 \\
Race & & & .71 \\
$\quad$ Minority & .76 & .81 & .69 \\
White & .72 & .78 & .72 \\
GPA & & & .67 \\
$4.00-3.50$ & .75 & .81 & .63 \\
$3.49-3.00$ & .70 & .76 & .78 \\
2.99 and below & .72 & &
\end{tabular}

reading score prediction vary for different subgroups of examinees? How reliable are the various score combinations?

Various combinations of the ACT Assessment raw scores and standard scores were correlated with a variety of reading test scores obtained from numerous ACT-user institutions over an extended period of time. On the basis of these studies, it can be concluded that (1) though a number of combinations of ACT test scores are predictive of independently measured reading performance, none is appreciably better than the ACT Composite; (2) all combinations are effective in predicting reading performance for various subgroups of students; and (3) the score combinations studied yield reliable indices of reading. Consequently, it was concluded that ACT test data can be useful for determining the need for reading instruction at the postsecondary level.

However, if ACT Assessment data are used to identify students in need of reading instruction,

Table 6

Correlations Between Actual and Predicted Scores for Various Subgroups using the 3 standard Score Combination

\begin{tabular}{|c|c|c|c|c|}
\hline & Mean & Mean & Difference & $\begin{array}{c}\text { Correlation } \\
\text { between }\end{array}$ \\
\hline & Predicted & Actual & $(P-A)$ & Actual \& Predicted \\
\hline \multicolumn{5}{|l|}{$\overline{\operatorname{sex}}$} \\
\hline Male & 58.0 & 57.6 & +.4 & .82 \\
\hline Female & 59.7 & 59.9 & -.2 & .80 \\
\hline \multicolumn{5}{|l|}{ Race } \\
\hline Minority & 50.6 & 51.9 & -1.3 & .81 \\
\hline White & 59.7 & 59.6 & 1.1 & .80 \\
\hline \multicolumn{5}{|l|}{ GPA } \\
\hline $4.00-3.50$ & 62.0 & 62.3 & -.3 & .77 \\
\hline $3.49-3.00$ & 56.3 & 56.1 & +.2 & .77 \\
\hline 2.99 and below & 55.2 & 54.5 & +.7 & .82 \\
\hline
\end{tabular}


they must be used judiciously. Correlations around .70 suggest that even in the Natural Science and Social Studies tests, factors other than reading skill are operating to determine student performance. But if the ACT Assessment data are used conservatively, students who might profit from further diagnostic testing and from remedial reading instruction can be identified. In those cases where ACT scores are already available as a part of the student's admissions record, significant increases in the efficiency of placement testing programs may accrue to institutions that use the ACT Composite as an initial screening measure in reading. Institutions electing to use ACT Assessment scores to make placement decisions in remedial reading are strongly urged to conduct local validation studies to determine the appropriateness of those placement decisions.

\section{References}

Kammann, R. A. Aptitude, study habits, and reading improvement. Journal of Developmental Reading, 1973, 6, 77-86.

Mist, P. K. An examination of the ACT program as a predictor of reading skills of community college freshmen. Unpublished manuscript, Southwestern Michigan College, Dowagiac, MI, 1970.

Munday, L. Correlates between ACT and other predictors of academic success in college. College and University, 1968, 44, 67-76.

Oliven, C. C. The 1975 Survey of Postsecondary Users of the ACT Assessment. Iowa City, IA: The American College Testing Program, 1975.

Rever, P. R., \& Kojaku, L. D. Access, attrition, test scores, and grades of college entrants and persistence: 1965-1973. Research in Higher Education, $1976,5,289-299$.

Schroeder, L. L. Prediction of Nelson-Denny scores based on ACT data. Unpublished manuscript, Burlington County College, Pemberton, NJ, 1975.

Cross, K. P. Beyond the Open Door. San Francisco: Jossey-Bass, 1971.

\section{Author's Address}

Richard J. Stiggins, Director of Test Development, ACT, PO Box 168, Iowa City, IA 52240 